Research, Society and Development, v. 9, n. 7, e839974781, 2020

(CC BY 4.0) | ISSN 2525-3409 | DOI: http://dx.doi.org/10.33448/rsd-v9i7.4781

\title{
Zygmunt Bauman vai ao cinema: filmes para entender a modernidade líquida
}

Zygmunt Bauman goes to the cinema: films to understand liquid modernity

Zygmunt Bauman va al cine: películas para entender la modernidad líquida

Recebido: 21/05/2020 | Revisado: 29/05/2020 | Aceito: 01/06/2020 | Publicado: 16/06/2020

\section{Rafael Montoito}

ORCID: https://orcid.org/0000-0002-3294-3711

Instituto Federal de Educação, Ciência e Tecnologia Sul-rio-grandense, Brasil

Email: xmontoito@gmail.com

Luize Castro Garim

ORCID: https://orcid.org/0000-0001-9447-6066

Instituto Federal de Educação, Ciência e Tecnologia Sul-rio-grandense, Brasil

Email: luizegarim@hotmail.com

\section{Resumo}

Este artigo visa colocar em diálogo algumas obras cinematográficas com os principais conceitos da modernidade líquida, termo cunhado pelo sociólogo polonês Zygmunt Bauman para caracterizar a época atual. Oriundo de uma dissertação que se propunha a discutir, num curso de formação de professores, a potencialidade didática do cinema como convite para uma melhor compreensão da modernidade líquida, este texto apresenta uma breve discussão sobre sua conceituação, seguida do estado do conhecimento construído a partir de pesquisas que consideraram algumas obras cinematográficas como representativas dos aspectos da modernidade líquida. A construção do estado do conhecimento propiciou perceber que as pesquisas encontradas trataram com maior destaque aspectos subjetivos da construção da identidade do indivíduo pós-moderno e, apenas em menor escala, discutiram as relações entre o indivíduo e grupos ou instituições sociais. Ao final, este artigo destaca e incentiva o uso do cinema com fins pedagógicos e deixa indicações de outras obras que podem incrementar o diálogo entre a sociologia de Bauman e as produções cinematográficas.

Palavras-chave: Bauman; Cinema; Modernidade líquida; Formação de professores.

\begin{abstract}
This paper aims to put in dialogue some cinematographic works with the main concepts of liquid modernity, a term coined by the Polish sociologist Zygmunt Bauman to characterize the
\end{abstract}


current era. Coming from a dissertation that proposed to discuss, in a teachers' training course, the didactic potential of cinema as an invitation to a better understanding of liquid modernity, this text presents a brief discussion about its conceptualization, followed by the state of knowledge constructed from researches that considered some cinematographic works as representative of liquid modernity aspects. The construction of knowledge state led to the realization that the research found dealt with more prominently subjective aspects of the construction of the postmodern individual's identity and, only to a lesser extent, discussed the relationships between the individual and social groups or institutions. In the end, this article highlights and encourages the use of cinema for pedagogical purposes and leaves indications of other works which can increase the dialogue between Bauman's sociology and cinematographic productions.

Keywords: Bauman; Cinema; Liquid modernity; Teachers' training.

\section{Resumen}

Ese artículo tiene como objetivo establecer un diálogo entre algunas películas con los conceptos más importantes de la modernidad líquida, término acuñado por el sociólogo polaco Zygmunt Bauman para caracterizar la era actual. A partir de una disertación que deseaba discutir, en un curso de formación docente, la potencialidad didáctica del cine como invitación para comprender mejor la modernidad líquida, este texto presenta una breve discusión sobre su conceptualización, seguida del estado del conocimiento constuído a partir de las investigaciones que consideraron algunas películas como representativas de los aspectos de la modernidad liquida. La elaboración del estado del conocimiento permitió percibir que las investigaciones encontradas se ocuparon con mayor profundidad de los aspectos subjetivos de la construcción de la identidad del individuo posmoderno y, en menor escala, discutieron las relaciones entre el individuo y grupos o instituciones sociales. En el final, este artículo destaca e incentiva el uso del cine con fines pedagógicos y sugiere otras películas que pueden promover el diálogo entre la sociologia de Bauman y las producciones cinematográficas.

Palabras clave: Bauman; Cine; Modernidad liquida; Formación docente.

\section{Introdução}

Este artigo é parte de uma dissertação que se propôs a problematizar aspectos da pósmodernidade por meio da escolha de produções cinematográficas, num curso de formação de 
professores ${ }^{1}$. Consideramos, neste aspecto, o professor como um multiplicador que poderá, posteriormente, estender estas questões a outras turmas e a outros alunos. A ideia central deste estudo era compreender melhor as linhas que tecem comportamentos e relações na pósmodernidade, considerando que o tempo presente incita e produz transformações que não ficam alheias aos muros da escola e que, várias vezes, não são abordadas pelos conteúdos escolares. Entendemos que ter mais clareza sobre os aspectos da pós-modernidade é importante para pensarmos em práticas pedagógicas que dialoguem com a atualidade e, por isso, toda a dissertação foi pensada com foco na formação de professores.

A escolha por propor estudos e diálogos intermediados por filmes se deu em virtude de considerarmos que não é tão simples estudar e compreender o tempo e as modificações presentes estando imersos nele, pois isso exige uma atitude de distanciamento que não tem sido incentivada pelas práticas atuais; pelo contrário, temos sido incentivados ao consumo, às relações superficiais, ao egoísmo, às mudanças abruptas e seguidas e à necessidade do novo, ações que vêm se naturalizando no comportamento humano e às quais Zygmunt Bauman, sociólogo polonês, acena vastamente em sua obra. Os filmes são aqui tomados, então, como facilitadores, como átrios para o estudo da pós-modernidade.

Este artigo visa colocar em diálogo algumas obras cinematográficas com os principais conceitos da modernidade líquida, termo cunhado pelo sociólogo polonês Zygmunt Bauman para caracterizar a época atual.

O artigo se divide em três partes: (1) o referencial teórico, ou seja, uma apresentação introdutória acerca das ideias principais de Bauman, sobretudo no que tange ao conceito de modernidade líquida, e da potencialidade pedagógica do cinema; (2) a metodologia utilizada na elaboração deste artigo, a saber, um estado do conhecimento de pesquisas já feitas que apontam filmes cujas histórias, em alguma medida, são metáforas para os escritos baumanianos; a ele, acrescentamos algumas reflexões pessoais e aprofundamentos teóricos sobre a modernidade líquida; (3) conclusões parciais sobre o uso pedagógico do cinema para a educação.

\footnotetext{
${ }^{1} \mathrm{O}$ curso Formação Pedagógica para Graduados não Licenciados é ofertado no Instituto Federal de Educação, Ciência e Tecnologia Sul-rio-grandense, Campus Pelotas, desde o segundo semestre de 2018. Nele há uma disciplina chamada Teorias Educacionais Contemporâneas, à qual esta pesquisa foi vinculada.
} 


\section{Referencial Teórico: Bauman vai ao cinema}

Na busca por entender melhor a sociedade pós-moderna, os escritos de Bauman são instrumentos que ajudam a "dar ordem ao mundo, [o que] significa dotá-lo de uma estrutura cognitiva, estritamente racional, na qual sabemos, com toda certeza, de que modo prosseguir e, no caminho, quem são os amigos, os inimigos e os estranhos" (Almeida, Gomes \& Bracht, 2016, p. 17).

Apoiar-nos em Bauman é essencial para que compreender a confusão cuja origem aparece já na formulação do conceito: afinal, o que é pós-moderno? Lampert (2005) não responde a essa pergunta diretamente, mas lançando mão de outras questões, tais como: seria ela uma revolução, uma renovação, uma ruptura ou uma ideologia? Seria uma crise da modernidade, uma saída dessa ou um período de transição? Seria mais moderna que a modernidade? Ela existe? Se existe, qual seu lugar na História e sua legitimidade?

O fato de não termos respostas diretas e simples para estas indagações não significa que a pós-modernidade não existe. Appignanesi \& Garratt (1997) dão-lhe status ontológico ao mapearem as transformações humanas no modo de ver, pensar e produzir que, de maneira inter-relacionada e não linear, a constituíram - e seguem constituindo-a - com a passagem dos anos. Os autores mostram como o panorama é complexo ao discutirem as modificações nas esferas da arte (que vai da crise da representação da realidade à não-representação e ao simulacro), da teoria (do estruturalismo da linguagem à ficção do eu e ao reconhecimento de que o saber é uma força de produção pós-industrial) e da história econômica (que inclui realidades simuladas, parques temáticos, guerras transmitidas pela tv, cibercultura e $\mathrm{o}$ zapping $^{2}$ como cultura, dentre outras coisas).

Deste cenário com delimitações tão sinuosas, Eagleton (1998) percebeu que a pósmodernidade alune a um período histórico específico, o qual questiona as noções clássicas de verdade, razão, identidade e objetividade, além das ideias de progresso ou emancipação universal, dos sistemas únicos e das metanarrativas ou dos fundamentos definitivos de explicação. A pós-modernidade, confusa e ainda em formação/transformação, apresenta-se ao indivíduo como uma sensação e uma aposta:

\footnotetext{
2 “O zapping nasceu com a chegada das emissões de múltiplos canais por cabo e por satélite, juntamente com a indispensável ajuda do controlo remoto. Esta pretensiosa cornucópia de escolha para satisfazer a diversidade do interesse individual acaba por fazer com que ninguém veja nada - a arte está em fazer zapping, a autocriação do seu próprio espetáculo pós-moderno" (Appignanesi \& Garratt, 1997, p. 152).
} 
Uma sensação de que a modernidade está falida; e de que a racionalização da vida é inaceitável e desumana; de que a promessa de progresso é uma ilusão e de que o universal é perigoso. Aposta porque os pós-modernos confiam na heterogeneidade e na diferença; afirmam a fragmentação de experiências; enfatizam a existência de micropoderes capilares no interior da sociedade e consideram ilusórios o poder do Estado e a denominação de classe (Lampert, 2005, p. 15-16).

"A pós-modernidade, que não tornou obsoleta a modernidade, que questiona a teoria cartesiana e que perdeu a âncora das metanarrativas, considera que há multicamadas de interpretar a realidade e que a dúvida é condição indispensável à reflexão" (Ibid., p. 21). Entretanto, ainda que evidentemente complexa e diversa no pensamento de estudiosos, um traço a que todos aludem é que ela se situa numa fase cultural do capitalismo, em seus estágios mais avançados, no qual as tecnologias têm poder de destaque na estrutura econômica (Shinn, 2008).

E é quando colocamos o capitalismo no centro de análises que visam a construir um melhor entendimento sobre a pós-modernidade que a obra de Bauman ganha uma importância fulcral. A partir dos novos desdobramentos do capitalismo, ele cunha o conceito de modernidade líquida ${ }^{3}$.

Para chegar a esse raciocínio de liquidez, Bauman trabalha com a ideia de "fluidez", como uma das qualidades dos líquidos. Nas palavras do autor, o que distingue os fluídos dos sólidos é que aqueles "não podem suportar uma força tangencial ou deformante quando imóveis" (Bauman, 2001, p. 7). Isso significa que a característica marcante do fluído é a mutabilidade, a deformação e a falta de resistência frente ao uso dessa força. Esse raciocínio é de grande importância para a compreensão do mundo líquido, sobre o qual o sociólogo traçará amplas análises, cujo excerto a seguir bem define:

Os líquidos se movem facilmente. Eles fluem, escorrem, esvaem-se, respingam, transbordam, vazam, inundam, borrifam, pingam, são filtrados, destilados; diferentemente dos sólidos não são facilmente contidos - contornam outros obstáculos, dissolvem outros e invadem ou inundam seu caminho. Do encontro com os sólidos emergem intactos, enquanto os sólidos que encontraram, se permanecem sólidos, são alterados - ficam molhados ou encharcados. A extraordinária mobilidade

\footnotetext{
3 À guisa de explicação, é importante ressaltarmos que, até alguns anos, o termo pós-modernidade era utilizado para se referir ao período histórico e, pós-modernismo, aos movimentos na política e na cultura. "Se os debates sobre o conceito de 'pós-modernidade' e 'pós-modernismo', que foram centrais para a teoria social dos anos oitenta, ocupam menos espaço hoje do que dez ou quinze anos atrás, isto talvez represente mais uma trégua do que um consenso sobre o uso dos conceitos. No campo específico da Sociologia, vários dos autores consagrados do nosso momento dizem não gostar do conceito (...), até Zygmunt Bauman, que, em tempos recentes, preferiu o termo de 'modernidade líquida' ao conceito de pós-modernidade que ele empregava em obra anterior (Adelman, 2009, p. 186). Considerando isso assumimos, neste texto, dependendo do autor citado, "pós-modernidade" e "pós-modernismo" como intercambiáveis embora, a partir deste ponto, aludamos preferencialmente à "modernidade líquida" devido a Bauman ser o cerne de toda esta pesquisa.
} 
dos fluidos é o que os associa à ideia de leveza (...). Essas são as razões para considerar fluidez ou liquidez como metáforas adequadas quando queremos captar a natureza da presente fase, nova de muitas maneiras, na história da modernidade (Ibid., p. 8-9).

Esta liquidez, que é o conceito medular das obras baumaninas, é retomada em vários dos livros de Bauman, por vezes comunicada com outras palavras:

O mundo que chamo de "líquido" porque, como todos os líquidos, ele jamais se imobiliza nem conserva sua forma por muito tempo. Tudo ou quase tudo em nosso mundo está sempre em mudança: as modas que seguimos e os objetos que despertam nossa atenção (uma atenção, aliás, em constante mudança de foco, que hoje se afasta das coisas e dos acontecimentos que nos atraíam ontem, que amanhã se distanciará das coisas e dos acontecimentos que nos instigam hoje); as coisas que sonhamos e que tememos, aquelas que desejamos e odiamos, as que nos enchem de esperanças e as que nos enchem de aflição (Bauman, 2011, p. 7).

Para o sociólogo, a história da modernidade pode ser separada em duas alegorias distintas: a dos sólidos (ou modernidade sólida) e a dos líquidos (modernidade líquida). Ambas possuem características comuns, pontos estratégicos que aproximam nosso tempo a seu antecessor cronológico:

A sociedade que entra no século XXI não é menos moderna que a que entrou no século XX; o máximo que se pode dizer é que ela é moderna de um modo diferente. $\mathrm{O}$ que a faz tão moderna como era mais ou menos há um século é o que distingue a modernidade de todas as outras formas históricas do convívio humano: a compulsiva e obsessiva, contínua, irrefreável e sempre incompleta modernização; a opressiva e inerradicável, insaciável sede de destruição criativa (ou de criatividade destrutiva, se for o caso: de "limpar o lugar" em nome de um "novo e aperfeiçoado" projeto; de "desmantelar", "cortar", "defasar", "reunir" ou "reduzir", tudo isso em nome da maior capacidade de fazer o mesmo no futuro - em nome da produtividade ou da competitividade) (Bauman, 2001, p. 40).

Percebemos, portanto, que vivemos uma forma de modernidade tanto quanto os nossos antepassados do século XIX. Contudo, há algumas propriedades importantes nos tempos atuais que os fazem únicos na história da humanidade. Bauman trata isso em dois aspectos, sendo o primeiro deles a decadência da antiga ilusão moderna:

da crença de que há um fím do caminho em que andamos, um telos alcançável da mudança histórica, um Estado de perfeição a ser atingido amanhã, no próximo ano ou no próximo milênio, algum tipo de sociedade boa, de sociedade justa e sem conflitos em todos ou alguns de seus aspectos postulados: do firme equilíbrio entre oferta e procura e a satisfação de todas as necessidades; da ordem perfeita, em que tudo é colocado no lugar certo (Bauman, 2011, p. 41). 
Mas não foi somente a perda de um caminho de segurança que o fim da modernidade sólida levou consigo. O que antes era coletivo e vislumbrado conjuntamente como sociedade - como, por exemplo, as lutas pelos direitos trabalhistas no século XIX, que eram pauta de toda uma categoria (a ação coletiva orientada pela classe) - passa a ser visto como uma tarefa privatizada, individualizada, recaindo o peso dessa responsabilidade sobre a unidade de cada ser humano (Bauman, 2001).

A sociedade como instituição, na visão baumaniana, desapareceu, mas sofreu mudanças severas. As classes não deixaram de existir, mas a luta conjunta foi dificultada por uma obrigação de reacomodação constante. A base sólida das sabedorias coletivas, hoje se tornou evasiva e volátil, se abstendo da coerção direta, por demais onerosa aos padrões da vida líquida.

Não se acredita mais que a "sociedade" seja um árbitro das tentativas e erros dos seres humanos - um árbitro severo e intransigente, por vezes rígido e impiedoso, mas de quem se espera ser justo e de princípios. Ela nos lembra, em vez disso, um jogador particularmente astuto, ardiloso e dissimulado, especializado no jogo da vida, trapaceando quando tem chance, zombando das regras quando possível - em suma, um perito em truques por baixo do pano que costuma apanhar todos os outros jogadores, ou a maioria deles, despreparados (Bauman, 2005, p. 58).

O que podemos perceber, então, dessas duas grandes características atribuídas por Bauman à modernidade líquida, é que essa forma de sociedade que surgiu transformou o cidadão em indivíduo: não uma individualização como a que outrora existiu, mas uma forma que exige uma modificação e mutação constantes, onde os próprios indivíduos são os responsáveis diários por formular sua própria identidade, sem a presença de um grupo social de apoio (Bauman, 2001).

Mas, então, quais as consequências, características e o que significa essa individualização tão presente na nova modalidade de vida líquido moderna? E, mais especificamente, como esta individualização atinge e ecoa nos cenários educacionais, na construção das identidades dos estudantes e na prática docente?

Algumas destas respostas podem ser encontradas nos próprios escritos de Bauman (1994), Bauman \& Leoncini (2018), outras em estudos como o de Zdradek (2019) e o de Fávero, Tonieto \& Cosálter (2019). Outrossim, tais obras não esgotam o assunto e nem o poderiam fazer, dada a já citada condição de constante mutabilidade. Considerando a máxima de Bauman - "vivemos em tempos líquidos: nada é para durar" (Bauman 2010) -, pensamos ser importante criar estratégias que visem a educar a sensibilidade e discutir, sobretudo nos 
cursos de formação de professores, a necessidade de estarmos atentos para reconhecer as mudanças e a pluralidade de comportamentos, relacionamentos e tensões sociais pelas estamos passando.

Considerando estas questões, decidimos fazer uma pesquisa que se valesse do cinema para provocar percepções outras e possíveis discussões, utilizando-nos da linguagem fílmica para clarificar - ou, ao menos, potencializar - situações arquetípicas da modernidade líquida. Entendemos que um filme, além de apenas divertir, pode também provocar sentimentos; ainda, que a relação do espectador com este tipo de produção artística não é passiva, isto é, as narrativas fílmicas não têm o poder de, sozinhas, forjar pensamentos, ideias e opiniões (Duarte, 2002): ao capturarem o espectador para dentro da história, os filmes convidam a um protagonismo ativo na construção de reflexões, cumprindo o papel "escola de vida" (Morin, 2003).

Assim, advogamos que o cinema pode ser utilizado como um instrumento de catarse contemporânea. Para o ensino, a arte cinematográfica é uma oportunidade valiosa e um recurso que não deve ser ignorado. Tendo partido dessa ideia, nosso primeiro passo na pesquisa foi, portanto, fazer um levantamento de filmes que pesquisas anteriores apontaram como sendo representativos dos principais traços da modernidade líquida. Este movimento de pesquisa gerou um estado do conhecimento, o qual é apresentado a seguir.

\section{Estado do Conhecimento: filmes para entender a modernidade líquida}

Este artigo diz respeito a uma pesquisa de natureza qualitativa, nos moldes caracterizados por Pereira, Shisuka, Parreira \& Shitsuka (2018). Cabe ressaltar que, ainda com relação a estes autores, a pesquisa foi elaborada a partir de uma revisão bibliográfica que orientou, posteriormente, a escolha dos filmes que inspiraram atividades e discussões com os professores graduandos. Contudo, neste artigo, estas atividades não serão comentadas, ficando esse limitado à discussão dos dados que a revisão bibliográfica propiciou-nos vislumbrar.

É-nos clara a ideia de que "qualquer trabalho de pesquisa inicia-se com uma pesquisa bibliográfica, procurando referências teóricas publicadas com o objetivo de recolher informações ou conhecimentos prévios sobre o tema a respeito do qual se procura a resposta" (Fonseca, 2002, p. 31-32). Na construção da dissertação, portanto, nossa primeira ação foi acessar a Biblioteca Digital Brasileira de Teses e Dissertações (BDTD) e o Banco de Teses da Coordenação de Aperfeiçoamento de Pessoal de Nível Superior (CAPES) à procura de trabalhos de conclusão de curso, dissertações e teses disponíveis, cujas temáticas pudessem 
ajudar-nos no acercamento do nosso objeto de pesquisa. O período de busca foi de 2009 a 2017, pois a dissertação feita a partir destes dados começou a ser elaborada em 2018, e as palavas-chaves utilizadas na busca foram Bauman e cinema.

A partir deste movimento, construímos o estado do conhecimento, que é um processo de "identificação, registro e categorização que levam à reflexão e síntese de uma determinada área, em um determinado espaço de tempo" (Morosini \& Fernandes, 2014, p. 155) que visa a propiciar, aos pesquisadores, um contato com o que já foi produzido anteriormente sobre o objeto pesquisado. No primeiro momento, desejávamos inteirar-nos do modo como os filmes foram apropriados como fonte para discussões das temáticas da modernidade líquida; no segundo, queríamos ver se os filmes que tínhamos em mente já haviam sido utilizados com a intenção de propiciar discussões na área da educação (o que não invalidaria nossas intenções, haja vista que o mesmo filme pode suscitar reflexões distintas em diferentes momentos, para demais pessoas).

O estado do conhecimento se propunha a responder a questão: Quais traços da modernidade líquida são mais perceptíveis nos filmes analisados? O processo de elaboração desta resposta, por não ser direto e imediato, enriqueceu nossa percepção sobre o tema pesquisado, conforme será comentado adiante. Vale ressaltar que, à volta da construção desta resposta, gravitaram outras informações que, se não eram as que nos interessavam inicialmente, acabaram por nos ajudar a conhecer melhor as metodologias utilizadas para se fazer pesquisas com obras cinematográficas, a despertar nosso interesse por outros teóricos de diversas áreas cujas obras dialogam com os escritos de Bauman e, sobretudo, apontaram-nos caminhos para compormos um mosaico interpretativo mais aprofundado das obras e do pensamento do sociólogo polonês.

O Quadro 1, a seguir, mostra o quantitativo de resultados encontrados nesta busca.

\section{Quadro 1 - Cinema / Bauman.}

\begin{tabular}{|c|c|c|c|c|c|c|c|}
\hline Palavras-chaves & \multicolumn{7}{|c|}{ ANO } \\
\hline Cinema/Bauman & 2009 & 2010 & 2013 & 2014 & 2015 & 2016 & Total \\
\hline TCCs & 1 & 1 & & 1 & & & 3 \\
\hline Dissertações & & 1 & 1 & 1 & 3 & 1 & 7 \\
\hline Total & 1 & 2 & 1 & 2 & 3 & 1 & 10 \\
\hline
\end{tabular}

Fonte: Autores, 2018.

O quadro mostra que a interlocução Bauman e cinema não foi objeto de investigação em todos os anos pesquisados, porém foi possível encontrar dez trabalhos, no total. 
Research, Society and Development, v. 9, n. 7, e839974781, 2020

(CC BY 4.0) | ISSN 2525-3409 | DOI: http://dx.doi.org/10.33448/rsd-v9i7.4781

Cada um deles foi lido atentamente e, após isso, foram eliminados os trabalhos que utilizavam as ideias de Bauman para comentar, entender ou estudar algum filme, pois o que nos interessava não era a "aplicação" das ideias baumanianas à obra cinematográfica, mas exatamente o contrário: perceber como os pesquisadores identificavam que determinado filme tinha potencial representativo dos aspectos da modernidade líquida, quase como se ele fosse uma metáfora ou exemplo das questões que a caracterizam. Este reagrupamento das referências pesquisadas levou-nos à elaboração do Quadro 2.

Quadro 2 - Trabalhos cujos filmes eram tomados como representações de aspectos da modernidade líquida.

\begin{tabular}{|c|c|c|c|c|c|c|c|}
\hline Palavras-chaves & \multicolumn{7}{|c|}{ ANO } \\
\hline Cinema/Bauman & 2009 & 2010 & 2013 & 2014 & 2015 & 2016 & Total \\
\hline TCCs & 1 & 1 & & 1 & & & 3 \\
\hline Dissertações & & 1 & 1 & & 1 & 1 & 4 \\
\hline Total & 1 & 2 & 1 & 1 & 1 & 1 & 7 \\
\hline
\end{tabular}

Fonte: Autores, 2018.

O quadro acima permite perceber que o quantitativo de obras diminuiu de dez para sete, pois foram descartadas, após a primeira leitura, três pesquisas (uma dissertação de 2014 e duas dissertações de 2015) que usavam Bauman como referencial teórico, mas não eram estudos sobre como determinado filme poderia ser tomado como representação dos pontos teóricos discutidos pelo sociólogo polonês.

O Quadro 3, a seguir, traz algumas informações relevantes sobre cada um destes sete trabalhos analisados. 
Research, Society and Development, v. 9, n. 7, e839974781, 2020

(CC BY 4.0) | ISSN 2525-3409 | DOI: http://dx.doi.org/10.33448/rsd-v9i7.4781

Quadro 3 - Principais informações dos trabalhos cujos filmes podem ser tomados como representações de aspectos da modernidade líquida.

\begin{tabular}{|c|c|c|c|c|c|c|}
\hline $\mathrm{N}^{\mathbf{o}}$ & Título / Tipo & Ano & Autor & Objetivo & Local & Palavras-chaves \\
\hline 1 & $\begin{array}{c}\text { Representações da } \\
\text { modernidade líquida } \\
\text { em Vicky Cristina } \\
\text { Barcelona } \\
\text { TCC }\end{array}$ & 2009 & $\begin{array}{c}\text { Maria Lina } \\
\text { Truccolo } \\
\text { Colgnachi }\end{array}$ & $\begin{array}{l}\text { Estudar as formas pelas quais } \\
\text { os personagens da obra } \\
\text { fílmica podem ser entendidos } \\
\text { enquanto representação do } \\
\text { que Zygmunt Bauman define } \\
\text { como modernidade líquida. }\end{array}$ & $\begin{array}{c}\text { Faculdade de } \\
\text { Biblioteconomia e } \\
\text { Comunicação - } \\
\text { UFRGS } \\
\text { (Porto Alegre/RS) }\end{array}$ & $\begin{array}{l}\text { Modernidade } \\
\text { Líquida. Bauman. } \\
\text { Prática Social. } \\
\text { Representação. } \\
\text { Woody Allen. }\end{array}$ \\
\hline 2 & $\begin{array}{l}\text { "Eu te amo": a } \\
\text { representação do } \\
\text { amor líquido no } \\
\text { filme de Arnaldo } \\
\text { Jabor } \\
\text { TCC }\end{array}$ & 2010 & $\begin{array}{l}\text { Pedro } \\
\text { Augusto } \\
\text { Fontoura } \\
\text { Argenti }\end{array}$ & $\begin{array}{l}\text { Estudar a representação do } \\
\text { amor pós-moderno no filme } \\
\text { "Eu te amo", do brasileiro } \\
\text { Arnaldo Jabor. }\end{array}$ & $\begin{array}{c}\text { Faculdade de } \\
\text { Biblioteconomia e } \\
\text { Comunicação - } \\
\text { UFRGS } \\
\\
\text { (Porto Alegre/RS) }\end{array}$ & $\begin{array}{c}\text { Eu te amo. } \\
\text { Arnaldo Jabor. } \\
\text { Cinema Brasileiro. } \\
\text { Amor. } \\
\text { Pós-modernidade. }\end{array}$ \\
\hline 3 & $\begin{array}{c}\text { Blade Runner: a } \\
\text { ficção científica e a } \\
\text { ética da ciência na } \\
\text { sociedade líquido- } \\
\text { moderna } \\
\text { Dissertação }\end{array}$ & 2010 & $\begin{array}{c}\text { Edilson } \\
\text { Rodrigues } \\
\text { Palhares }\end{array}$ & $\begin{array}{c}\text { Demonstrar a relação } \\
\text { dicotômica da feitura do } \\
\text { filme entre produção } \\
\text { mercantilista e cinema de } \\
\text { autor, extraindo dessa } \\
\text { premissa sua legitimidade } \\
\text { como uma Ficção Científica } \\
\text { de comprometimento social, } \\
\text { possibilitando uma } \\
\text { abordagem reflexiva quanto } \\
\text { aos limites éticos da ciência } \\
\text { na atual condição da } \\
\text { modernidade. }\end{array}$ & $\begin{array}{l}\text { Programa de Pós- } \\
\text { graduação em } \\
\text { Ciências Sociais - } \\
\text { PUC }\end{array}$ & $\begin{array}{c}\text { Blade Runner. } \\
\text { Ficção Científica. } \\
\text { Sociedade líquido- } \\
\text { moderna. } \\
\text { Ética e Ciência. }\end{array}$ \\
\hline 4 & $\begin{array}{c}\text { Maria Antonieta: } \\
\text { uma abordagem } \\
\text { cinematográfica do } \\
\text { indivíduo } \\
\text { contemporâneo } \\
\text { Dissertação }\end{array}$ & 2013 & $\begin{array}{l}\text { Moreno } \\
\text { Cruz } \\
\text { Osório }\end{array}$ & $\begin{array}{c}\text { Analisar o filme Maria } \\
\text { Antonieta e procurar } \\
\text { demonstrar que a obra } \\
\text { dirigida por Sofia Coppola é } \\
\text { capaz de proporcionar um } \\
\text { significado relacionado à } \\
\text { condição existencial do } \\
\text { indivíduo na } \\
\text { contemporaneidade. }\end{array}$ & $\begin{array}{c}\text { Programa de Pós- } \\
\text { graduação em } \\
\text { Comunicação Social } \\
\text { - PUC } \\
\text { (Porto Alegre/RS) }\end{array}$ & $\begin{array}{c}\text { Cinema. } \\
\text { Sociologia. } \\
\text { Análise Fílmica. } \\
\text { Contemporaneidade. }\end{array}$ \\
\hline 5 & $\begin{array}{l}\text { A sociedade líquida } \\
\text { e os efeitos da } \\
\text { tecnologia: uma } \\
\text { análise do filme } \\
\text { Wall-e } \\
\text { TCC }\end{array}$ & 2014 & $\begin{array}{c}\text { Luciana } \\
\text { Nunes } \\
\text { Kurtz }\end{array}$ & $\begin{array}{l}\text { Analisar a relação existente } \\
\text { entre sociedade e tecnologia } \\
\text { na animação Wall-e, } \\
\text { utilizando os embasamentos } \\
\text { teóricos de Zygmunt Bauman } \\
\text { sobre a sociedade moderna. }\end{array}$ & $\begin{array}{c}\text { Curso de } \\
\text { Publicidade e } \\
\text { Propaganda da } \\
\text { Faculdade de } \\
\text { Comunicação - UPF } \\
\text { (Passo Fundo/RS) }\end{array}$ & $\begin{array}{c}\text { Sociedade Moderna. } \\
\text { Indústria Cultural. } \\
\text { Tecnologia. } \\
\text { Cinema. Zygmunt } \\
\text { Bauman. } \\
\text { Wall-e. }\end{array}$ \\
\hline 6 & $\begin{array}{c}\text { A representação do } \\
\text { mal-estar líquido no } \\
\text { cinema de Michael } \\
\text { Haneke } \\
\text { Dissertação }\end{array}$ & 2015 & $\begin{array}{c}\text { Lucas } \\
\text { Pereira } \\
\text { Cassales }\end{array}$ & $\begin{array}{c}\text { Analisar a obra do diretor } \\
\text { austríaco Michael Haneke, } \\
\text { posicionando-a como uma } \\
\text { representação } \\
\text { cinematográfica do mal-estar } \\
\text { líquido. }\end{array}$ & $\begin{array}{c}\text { Programa de Pós- } \\
\text { graduação em } \\
\text { Comunicação Social } \\
\text { - PUC } \\
\text { (Porto Alegre/RS) }\end{array}$ & $\begin{array}{c}\text { Cinema. } \\
\text { Mal-estar. Haneke. } \\
\text { Bauman }\end{array}$ \\
\hline 7 & $\begin{array}{l}\text { A Constituição da } \\
\text { identidade na pós- } \\
\text { modernidade: o } \\
\text { simulacro da } \\
\text { realidade } \\
\text { Dissertação }\end{array}$ & 2016 & $\begin{array}{c}\text { Fernando } \\
\text { Maluf Dib } \\
\text { Oliveira }\end{array}$ & $\begin{array}{l}\text { Analisar como se constituem } \\
\text { as identidades na pós- } \\
\text { modernidade, momento em } \\
\text { que ocorre uma crise de } \\
\text { direcionamento na formação } \\
\text { das identidades quando } \\
\text { comparadas ao período } \\
\text { moderno. }\end{array}$ & $\begin{array}{l}\text { Programa de Pós- } \\
\text { graduação em } \\
\text { Ciências Sociais - } \\
\text { UFU }\end{array}$ & $\begin{array}{c}\text { Identidade. } \\
\text { Modernidade. } \\
\text { Pós-modernidade. } \\
\text { Pós-modernismo. }\end{array}$ \\
\hline
\end{tabular}

Fonte: Autores, 2018. 
Este quadro revela que nenhuma das pesquisas foi feita no âmbito da formação de professores, o que nos fez refletir sobre a pertinência do nosso estudo.

Feita uma leitura atenta desses trabalhos, sem perder o foco da questão que queríamos responder, porém mantendo nosso olhar atento a outras particularidades que emergissem de forma interessante, destacamos os apontamentos subsequentes. Vale ressaltar que as citações das obras de Bauman que trazemos neste momento são acréscimos nossos que responderam à necessidade de aproximar a temática discutida nos filmes com os escritos do sociólogo, tendo em vista momentos posteriores de utilização destes filmes em atividades de estudos no curso de formação de professores. Tais citações não são parte, necessariamente, dos trabalhos analisados, mas surgem do nosso movimento de cotejamento entre o que foi pesquisado e, os escritos de Bauman e clarificam o diálogo entre a obra fílmica e as ideias acerca da pósmodernidade.

O primeiro trabalho analisado, intitulado "Representações da modernidade líquida em Vicky Cristina Barcelona”, da pesquisadora Colnaghi (2009), tinha como objetivo estudar as formas pelas quais os personagens da obra fílmica podem ser entendidos enquanto representação do que Bauman define como modernidade líquida. A pesquisa, que considera o cinema como uma prática social, foi desenvolvida com base no estudo dos personagens, através de falas ou diálogos, comparando-os aos conceitos de modernidade líquida. Para tanto, a autora se concentrou nas principais características que permeiam a obra de Bauman, definindo modernidade líquida e felicidade líquida. No desenvolvimento da pesquisa, a pesquisadora identificou nas personagens traços que caracterizam o conceito de felicidade líquida de Bauman, tripartido em: vida como obra de arte, identidade e fragilidade dos laços humanos.

Para Colnaghi (2009), o cinema é mais que mera forma de representação, sendo verdadeira testemunha de determinada era e, por isso, acredita que o propósito da sua monografia foi o de representar os conceitos de Bauman através do filme "Vicky Cristina Barcelona" (2008) e de demonstrar que o cinema, por ser um meio de comunicação de massa, sedimenta na cultura modos de vida ainda não completamente compreendidos. Ao final, ela conclui que as diferentes personalidades do filme encontram correspondentes reais na sociedade líquida moderna, razão pela qual entendemos que essa obra tem potencial para colocar em discussão a vã perseguição da felicidade enquanto telos.

Sobre felicidade, Bauman (2009) diz: 
Poderíamos até dizer que nossa era moderna começou verdadeiramente com a proclamação universal à busca da felicidade, e da promessa de demonstrar sua superioridade em relação às formas de vida que ela substituiu tornando essa busca menos árdua e penosa, e ao mesmo tempo mais eficaz (Bauman, 2009, p. 08).

No entanto, a modernidade líquida causa no indivíduo a sensação de estar num abismo existencial, e paulatinamente a felicidade subjetiva foi ficando refém de uma felicidade vendida em suaves prestações ou à vista, em qualquer site com entrega a domicílio ou shopping próximo. "Como solução para todo esse abismo existencial, criado pela modernidade líquida, os mercados agora materializaram a ideia de felicidade, destruindo o pensamento de felicidade subjetiva e transformando-a em algo palpável, real e fixo" (Nascimento \& Silva, 2019, p. 121).

O segundo trabalho analisado, intitulado "“Eu te amo', a representação do amor pósmoderno no filme de Arnaldo Jabor", do pesquisador Argenti (2010), tinha como objetivo estudar a representação do amor pós-moderno no filme "Eu te amo" (1981). Em sua pesquisa, o autor delimitou amor como uma expressão cultural cujas qualidades são atribuídas com base nos valores sociais e temporais, descrevendo-o através de duas bases teóricas principais: a história do amor no Brasil, conforme estudos da historiadora e professora brasileira Mary Del Priore, e o conceito de amor líquido de Bauman. Seu estudo também compreende o cinema como prática social e o filme como um produto cultural de massa que reflete as concepções e os paradigmas vigentes em sua época e sociedade.

Com viés qualitativo e exploratório, Argenti (2010) fez uso da pesquisa bibliográfica sobre os elementos teóricos e da sistematização proposta por Graeme Turner, reconhecido professor e teórico austríaco no campo dos estudos culturais e de mídia, para a análise cinematográfica sob o paradigma do cinema como prática social. Essa análise considera aspectos do texto (elementos narrativos) e do contexto (ambientação histórico-cultural da sociedade).

Para desenvolver seu trabalho, em um primeiro momento, o autor realizou uma contextualização histórica do Brasil no período em que a obra foi lançada. Foram abordados os pressupostos filosóficos dos elementos que constituem o amor (tema central da obra), analisando o histórico brasileiro a respeito desse sentimento (com base nos estudos de Mary Del Priore) e a pós-modernidade (centrada nas conceituações de Bauman). Posteriormente foi feita uma síntese das proposições teóricas apresentadas, formulando três categorias de análise com base na articulação dos pressupostos de Bauman sobre o amor pós-moderno: "amor enquanto jogo de poder", "fetichismo dos corpos" e "amor como produto". Em seguimento, o 
autor dedicou-se à análise do filme em si, trazendo informações detalhadas sobre seu idealizador e sobre os artistas envolvidos, bem como sobre os aspectos técnicos, estéticos e logísticos da produção. Por último, fez uma análise da representação do amor pós-moderno de acordo com os conceitos teóricos e as metodologias escolhidas.

O pesquisador, sustentado pela teoria de Bauman, concluiu que o diretor representou o amor em sua obra com traços das características do amor pós-moderno. Neste aspecto, o filme nos chama a atenção por antecipar questões que há pouco tempo tomaram fôlego nas discussões sociais, trazendo à luz comportamentos e práticas sexuais que antes eram relegadas por pudicícia ou receio de julgamentos sociais. As categorias elencadas pelo pesquisador "amor enquanto jogo de poder", "fetichismo dos corpos" e "amor como produto" - são bastante representativas dos amores líquidos e da insegurança dos relacionamentos afetivos em voga na pós-modernidade e mostram que diversos comportamentos atuais tiveram origem no passado, motivo que dificulta escolher uma data ou marco que represente o começo da pós-modernidade: não é possível determinar quando o amor se liquefez.

Assim como a modernidade líquida incita a busca desenfreada pela felicidade inatingível, ela o faz nas relações amorosas. A busca por novas conquistas e parceiros que se moldem às expectativas pessoais é, para muitos, viciantes; os laços afetivos são frouxos porque se naturalizou a expectativa de que "o próximo amor será uma experiência ainda mais estimulante do que a que estamos vivendo atualmente, embora não tão emocionante ou excitante quanto a que virá depois" (Bauman, 2004, p. 19).

O terceiro trabalho analisado, intitulado "Blade Runner: a ficção científica e a ética da ciência na sociedade líquido-moderna", do pesquisador Palhares (2010), tinha como objetivo demonstrar a relação dicotômica da feitura do filme entre produção mercantilista e cinema de autor, extraindo dessa premissa sua legitimidade como uma ficção científica de comprometimento social que possibilita uma abordagem reflexiva quanto aos limites éticos da ciência na atual condição da pós-modernidade. Como metodologia de estudo, o autor se baseou em revisão bibliográfica sobre parte da produção acadêmica que aborda o filme, assim como em uma releitura de informações recolhidas ao longo de 25 anos de admiração da obra.

O trabalho foi desenvolvido analisando recortes de "Blade Runner", filme dirigido pelo cineasta Ridley Scott, e se concentrando na forma com que os limites éticos da ciência são apresentados em relação a uma sociedade de consumo, representada na cenografia de uma Los Angeles futurista (para um filme lançado em 1982, 2019 era um futuro distante). Como argumento, o autor sustenta que "Blade Runner" é uma obra que apresenta um futuro distópico, em que as consequências da produção capitalista aliadas a uma ciência sem 
consciência degradaram por completo a natureza, trazendo consigo grandes transtornos sociais e inusitados retrocessos na forma de exploração do trabalho.

Ao longo da pesquisa, o autor analisou o processo de produção de "Blade Runner", a relação do filme com o romance literário que deu origem à adaptação cinematográfica (“Androides sonham com ovelhas elétricas?”, escrito por Philip K. Dick e publicado pela primeira vez em 1968), com a ficção científica de natureza distópica e a concepção que o filme apresenta de uma metrópole do futuro em justaposição ao conceito de sociedade líquido moderna de Bauman. Por último, o autor fez um apontamento de que "Blade Runner" oferece continuidade à obra "Frankenstein" (Mary Shelley), pois revela a ideia de que a ciência precisa ter consciência ética, analisando essa visão sob os pressupostos de Edgar Morin, antropólogo e filósofo francês, de forma que os efeitos negativos que possam advir de seu manuseio aético não se voltem contra a humanidade.

A partir de todo seu estudo, o autor acredita que "Blade Runner", como um tipo de ficção científica consciente de seu papel na educação humana, contribui para a reflexão sobre a ética científica na sociedade da modernidade líquida. Afirmamos, em coro com o pesquisador, que este filme pode servir para alertar, de maneira pedagógica, para o fato de que as opções na aplicação das descobertas científicas devem fazer parte de um debate geral, sendo a população esclarecida de que as coisas não são tão simplistas quanto parecem, e que esse debate deve e pode começar na escola. No campo pessoal, é preciso instrumentalizar-se eticamente, mas de uma maneira não endurecida ou definitiva, pois

A proposta de tornar os indivíduos universalmente morais através da transferência de suas responsabilidades morais para os legisladores falhou, assim como a promessa de fazer todos livres do processo. Sabemos agora que vamos enfrentar para sempre dilemas morais sem soluções boas sem nenhuma ambiguidade (ou seja, universalmente acordadas e incontestadas), e que nunca vamos ter certeza onde se podem encontrar essas soluções; nem sequer se seria bom encontrá-las (Bauman, 2018, p. 49-50).

O quarto trabalho analisado, intitulado "Maria Antonieta: uma abordagem cinematográfica do indivíduo contemporâneo", do pesquisador Osório (2013), tinha como objetivo analisar o filme "Maria Antonieta" (2006) e procurar demonstrar que a obra dirigida por Sofia Coppola é capaz de problematizar a condição existencial do indivíduo na contemporaneidade. Em um primeiro momento, o trabalho abordou o indivíduo a partir das teorias sociológicas de Bauman e do sociólogo francês Michel Maffesoli, especificamente no posicionamento que os autores têm a respeito da situação do homem contemporâneo. 
Posteriormente, o autor apresenta uma análise do filme, aproximando-o do conceito de desconforto dionisíaco-líquido, criado com base nesses dois pensadores.

Para alcançar seu objetivo, Osório (2013) usa como aporte metodológico uma técnica de análise fílmica de David Bordwell, teórico norte-americano de cinema e historiador de filmes, sendo ela a responsável por aproximar o conceito sociológico ao filme, demonstrando a possibilidade de que os sentidos necessários para a consolidação de um significado sejam construídos. Osório (2013) também mostra que a trajetória da personagem principal é caracterizada como um movimento pendular entre a modernidade líquida de Bauman e a pósmodernidade de Maffesoli.

Ao final, o autor acredita que a análise realizada revela Sofia Coppola como uma diretora sensível à existência contemporânea, pois ela realizou um filme que é passível de uma interpretação cujos fundamentos foram incorporados da sociologia de dois autores que tentam explicar os impactos da pós-modernidade nos indivíduos.

As questões acerca da identidade, debatidas por Bauman em suas obras, têm contornos distintos daqueles das épocas anteriores. A produção das identidades atuais é tema caro para a educação, que lida com a pluralidade de seres e formas de expressão em constante movimento e, por isso, é preciso reconhecermos “que o 'pertencimento' e a 'identidade' não têm a solidez de uma rocha, não são garantidos para toda a vida, são bastante negociáveis e renegociáveis" (Bauman, 2005, p. 17). Isso equivale a dizer que construímos nossas identidades em detrimento de termos nascido com elas (Ibid.) e, indubitavelmente, as práticas e ambientes educacionais desempenham um papel neste processo.

O quinto trabalho analisado, intitulado "A sociedade líquida e os efeitos do desenvolvimento da Tecnologia: uma análise do filme Wall-e”, da pesquisadora Kurtz (2014), tinha como objetivo analisar a relação existente entre sociedade e tecnologia na animação "Wall-e" (2008), produzida pela Disney-PIXAR, utilizando os embasamentos teóricos de Bauman sobre a sociedade moderna. A autora escolheu a pesquisa qualitativa como viés metodológico de seu trabalho e justificou seu interesse no tema por entender que se faz necessário abordar a relação entre homem e tecnologia no processo de formação do hábito de consumo.

O desenvolvimento do estudo ocorreu em três capítulos. No primeiro foi discutida a escola de Frankfurt e o surgimento da Indústria Cultural, bem como seu poder e influência sobre a sociedade e seus hábitos de consumo; o segundo capítulo tratou da apresentação da animação objeto do estudo, descrevendo seu enredo e identificando a mensagem proposta; no terceiro e último capítulo são apresentados a metodologia e o estudo analítico do filme. 
A relevância da pesquisa está, segundo Kurtz (2014), na percepção, facilitada a partir de um produto cultural de massa, da representação da sociedade contemporânea e da maneira com que os conceitos baumanianos podem ser visto na cultura em que estamos inseridos. A nosso ver, o filme problematiza questões atualíssimas sobre o consumo das tecnologias e seu descarte e, se lembrarmos que Bauman (1994) adverte para o fato de que o jovem está sendo tratado como uma lata de lixo pela indústria do consumo, "Wall-E" pode ajudar a compor um momento pedagógico de estudos que traga estes assuntos à tona.

Sobre esta questão, o sociólogo polonês analisa, claramente, que a falta de perspectivas de trabalho para o jovem atual não o exime de um papel fundamental para o capitalismo da modernidade líquida: o de consumidor.

De fato, os jovens não são plena e inequivocadamente dispensáveis. O que os salva da dispensabilidade total - embora por pouco - e lhes garante certo grau de atenção dos adultos é sua real e, mais ainda, potencial contribuição à demanda de consumo (...) Pensa-se sobre a juventude e logo se presta atenção a ela como "um novo mercado" a ser "comodificado" e explorado. "Por meio da força educacional de uma cultura que comercializa todos os aspectos da vida das crianças, usando a internet e várias redes sociais, e novas tecnologias de mídia, como telefones celulares", as instituições empresariais buscam "imergir os jovens num mundo de consumo em massa, de maneiras mais amplas e diretas que qualquer coisa que possamos ter visto no passado" (Ibid., p. 52).

O sexto trabalho analisado, intitulado "A representação do mal-estar líquido no cinema de Haneke", do pesquisador Lucas Pereira Cassales (2015), tinha como objetivo analisar a obra do diretor austríaco Michael Haneke, posicionando-a como uma representação cinematográfica do mal-estar líquido. $\mathrm{O}$ autor optou por criar um modelo metodológico híbrido de análise, costurando aspectos analíticos e teóricos de forma equilibrada, baseandose nos métodos de Jacques Aumont, teórico de cinema e professor universitário francês, e Dubois, pesquisador francês da área de imagem. Para o estudo foram analisados os dois primeiros longa-metragens de Michael Haneke, "O sétimo continente" (1989) e "O vídeo de Benny" (1992), considerados pelo pesquisador como as duas obras que mais possuem elementos relacionados com o mal-estar líquido.

Em um primeiro momento, Cassales (2015) fez um levantamento histórico e social acerca dos elementos que compõe o mal-estar líquido e, posteriormente, estudou seus conceitos formadores por meio do trabalho de Jean Baudrillard, sociólogo e filósofo francês, e da teoria da modernidade líquida de Bauman; a partir destes referenciais, caracterizou o mal- 
estar líquido. Na sequência, trouxe a figura de Michael Haneke como um diretor de cinema autoral, e apresentou sua filmografia como representativa para o estudo do mal-estar líquido.

Para o autor, a pertinência de seu trabalho parte da sensação que parece permear todas as sociedades historicamente conhecidas: a de que algo não está bem. Contudo, Cassales (2015) acredita que nunca antes essa sensação foi tão confusa e exacerbada, o que se deve, provavelmente, segundo ele, às constantes e intensas revoluções tecnológicas e sociais ocorridas na modernidade líquida.

Tal qual observamos na pesquisa feita a partir do filme "Eu te amo", em consonância com o que Cassales (2015) aponta, o cinema parece ter um caráter antecipatório, pois filmes do século passado já acenavam às condições do mal-estar líquido. Segundo Bauman e Donskis (2019),

O mal está à espera e à espreita nos incontáveis buracos negros de um espaço social profundamente desregulamentado - em que a competição feroz e o estranhamento mútuo substituíram a cooperação e a solidariedade, enquanto a individualização forçada solapa o poder aglutinador dos vínculos inter-humanos (...). Em seus atuais esconderijos, o mal é difícil de localizar, desmascarar, remover e evacuar. Ele pula fora sem avisar e atinge aleatoriamente, sem uma explicação racional. $\mathrm{O}$ resultado é um ambiente social comparável a um campo minado, que sabemos estar cheio de explosivos e no qual temos toda a certeza de que mais cedo ou mais tarde ocorrerão explosões, embora sejamos incapazes de inferir quando e onde (Bauman \& Donskis, 2019, p. 49-50).

Considerando, novamente, que estarmos imersos nessa sociedade e neste tempo embaça, de certo modo, nosso julgamento e percepção, entendemos que os filmes de Haneke podem ajudar a desvelar estes sentimentos que têm produzido muitas angústias, inseguranças e doenças emocionais.

O sétimo trabalho analisado, intitulado “A constituição da identidade na pósmodernidade: o simulacro da realidade", do pesquisador Oliveira (2016), tinha como objetivo analisar como se constituem as identidades sociais na pós-modernidade, etapa em que ocorre uma crise de direcionamento na formação das identidades, se comparadas ao período da modernidade. O desenvolvimento da pesquisa, segundo Oliveira (2016), se deu a partir da problematização da transformação do indivíduo frente às mudanças decorrentes da cultura pós-moderna, de consumo e seu referencial dominante, considerando que a cultura atua sobre a transformação da personalidade individual.

O pesquisador analisou como o surgimento e a emancipação da modernidade, com as suas características, contribuíram para a constituição da identidade e o nascimento do 
individualismo, utilizando como embasamento o arcabouço teórico do sociólogo francês Alain Touraine, além das ideias de Bauman. Como elemento ilustrativo de sua discussão teórica acerca do surgimento do simulacro e de uma hiper-realidade, o autor se utilizou do filme "Ela" (2013), a fim de demonstrar a possível relação estabelecida entre o simulacro e o indivíduo nas sociedades contemporâneas, conforme discorridas nos estudos de Fredric Jameson, crítico literário e teórico marxista, e Jean Baudrillard, sociólogo e filósofo francês.

Como conclusão, Oliveira (2016) acredita que sua pesquisa apresenta um pano de fundo coerente com as sociedades contemporâneas, mas se questiona: será possível conceituar essas sociedades como pós-modernas ou são elas apenas frutos do desenvolvimento cultural e suas múltiplas características? Ainda que não possamos responder completamente as questões do autor, percebemos que o filme "Ela" (um romance distópico em que um escritor solitário se apaixona por Samantha, o sistema operacional de seu computador) afortaleza discussões acerca dos vínculos afetivos da sociedade líquido-moderna e da dependência humana das tecnologias virtuais, diversas vezes comentados nos escritos de Bauman, como no excerto a seguir:

Uma mensagem brilha na tela em busca de outra. Seus dedos estão sempre ocupados: você pressiona as teclas, digitando novos números para responder às chamadas ou compondo suas próprias mensagens. Você permanece conectado - mesmo estando em constante movimento, e ainda que os remetentes ou destinatários invisíveis das mensagens recebidas e enviadas também estejam em movimento, cada qual seguindo suas próprias trajetórias. Os celulares são para pessoas em movimento. Você nunca perde de vista o seu celular (...). Estando com seu celular, você nunca está fora ou longe. Encontra-se sempre dentro - mas jamais trancado em um lugar. Enclausurado numa tela cheia de mensagens, você está invulnerável (Bauman, 2004, p. 79-80).

Refletir sobre a dependência das tecnologias virtuais, sobretudo do celular, parece-nos bastante relevante para a formação de professores, haja vista a relação diferenciada que os estudantes - sobretudo os mais jovens - têm atualmente com os ambientes virtuais e com as redes sociais; ainda, vemos o modo como essas têm capturado para dentro de si as relações de trabalho - e, por conseguinte, o trabalhador - como um novo organizador da tessitura social e das relações de poder.

As descrições e comentários feitos até aqui consideraram, em sua construção, os trabalhos analisados separadamente. Mas o que podemos inferir ao tomá-los conjuntamente? O que apontam, revelam e nos permitem pensar se percebemos esta produção acadêmica com as palavras-chaves "Bauman" e "cinema" em sua coletividade? E, principalmente, que 
(CC BY 4.0) | ISSN 2525-3409 | DOI: http://dx.doi.org/10.33448/rsd-v9i7.4781

resposta podemos dar à questão que norteou nosso estado do conhecimento? Faremos agora algumas considerações para encerrar esta seção.

Num primeiro momento, destacamos que nenhuma destas pesquisas foi base para uma intervenção pedagógica, porém todas concluem acerca da potencialidade dos filmes escolhidos como metáfora dos comportamentos da modernidade líquida. A partir daí, a transposição destes filmes para o cenário educativo, considerando grupos de estudo ou trabalhos em aula, acena-se como viável. Isso deu-nos algumas pistas para pensarmos, nos outros momentos da construção da dissertação, em como analisar e fazer uso de um filme para se planejar momentos pedagógicos.

Outro ponto que nos chamou a atenção é que as pesquisas usaram, mais fortemente, referenciais teóricos atinentes às áreas do cinema, da construção da imagem, da sociologia e da filosofia. Obviamente, as interlocuções destes com as obras de Bauman são pertinentes; entretanto, nosso olhar tem se constituído no campo da educação e, portanto, pensar estes filmes num curso de formação de professores incita à procura de referências outras para, com eles, estabelecer diálogos. Isto é exequível e enriquecerá ainda mais as percepções que podem ser depreendidas dos filmes.

Por fim, com relação à questão Quais traços da modernidade líquida são mais perceptíveis nos filmes analisados? concluímos que os trabalhos elencados priorizaram elementos da constituição do individuo na modernidade líquida. Para explicar melhor esta percepção, tomemos o excerto a seguir, que resume seus principais pontos teóricos:

A modernidade líquida é um momento, em que a sociabilidade humana experimenta transformação nos seguintes processos:

- a metamorfose do cidadão (como sujeito de direitos e deveres), em indivíduo em busca de afirmação no espaço social;

- a passagem de estruturas de solidariedade coletiva para as de disputa e competição;

- o enfraquecimento de sistemas de proteção estatal às intempéries da vida, gerando um permanente ambiente de incerteza;

- a colocação da responsabilidade por eventuais fracassos, no plano individual;

- o fim do planejamento a longo prazo;

- o divórcio e a iminente apartação total entre poder e política (Sá \& Retz, 2015, p. 87).

Este resumo dá um pouco da noção da abrangência dos escritos de Bauman, cujas obras refletem não apenas sobre as transformações que a modernidade líquida inflige sobre os indivíduos (consigo mesmo e com o outro), mas também aquelas entre os indivíduos e as estruturas sociais (como, por exemplo, a configuração da comunidade, as relações de trabalho, 
a globalização, a riqueza de poucos em detrimento da pobreza de tantos, imigração e questões éticas etc). Sendo assim, embora compreendamos facilmente que, estando o indivíduo imerso numa sociedade, ele não pode ser pensado isoladamente, percebemos que apenas as temáticas da ética e do consumo, enquanto ações coletivas que colocam o homem agindo com demais grupos sociais, foram contempladas pelas pesquisadas que encontramos. A maioria delas, por conseguinte, refletiu sobre aspectos mais subjetivos da constituição da identidade, tais como as sensações de mal-estar e os vínculos afetivos.

Mostramos, no Quadro 4, como percebemos a aproximação das pesquisas encontradas com alguns conceitos importantes que permeiam as obras de Bauman, num esforço hermenêutico de categorização. Na coluna da direita sugerimos, a quem quiser adensar os estudos destes tópicos, ao menos um livro do sociólogo que dá destaque ao tema.

Quadro 4 - Síntese das pesquisas analisadas com relação às obras de Bauman.

\begin{tabular}{|c|c|c|c|}
\hline $\mathbf{N}^{\mathbf{0}}$ & Título & Conceitos-chaves & Obra de Bauman \\
\hline 1 & $\begin{array}{c}\text { Representações da modernidade } \\
\text { líquida em Vicky Cristina } \\
\text { Barcelona }\end{array}$ & $\begin{array}{l}\text { Relações afetivas; } \\
\text { Felicidade }\end{array}$ & $\begin{array}{l}\text { A arte da vida; } \\
\text { Amor líquido }\end{array}$ \\
\hline 2 & $\begin{array}{c}\text { "Eu te amo": a representação do } \\
\text { amor líquido no filme de Arnaldo } \\
\text { Jabor }\end{array}$ & Relações afetivas & Amor líquido \\
\hline 3 & $\begin{array}{c}\text { Blade Runner: a ficção científica } \\
\text { e a ética da ciência na sociedade } \\
\text { líquido-moderna }\end{array}$ & Ética & $\begin{array}{c}\text { A ética é possível num mundo de consumidores? } \\
\text { Ética pós-moderna }\end{array}$ \\
\hline 4 & $\begin{array}{l}\text { Maria Antonieta: uma abordagem } \\
\text { cinematográfica do indivíduo } \\
\text { contemporâneo }\end{array}$ & Moreno Cruz Osório & $\begin{array}{c}\text { Identidade } \\
\text { A individualidade numa época de incertezas }\end{array}$ \\
\hline 5 & $\begin{array}{l}\text { A sociedade líquida e os efeitos } \\
\text { da tecnologia: uma análise do } \\
\text { filme Wall-e }\end{array}$ & Relações de consumo & $\begin{array}{c}\text { Capitalismo parasitário } \\
\text { A ética é possível num mundo de consumidores? }\end{array}$ \\
\hline 6 & $\begin{array}{c}\text { A representação do mal-estar } \\
\text { líquido no cinema de Michael } \\
\text { Haneke }\end{array}$ & Mal-estar & $\begin{array}{c}\text { Mal líquido } \\
\text { O mal-estar na pós-modernidade }\end{array}$ \\
\hline 7 & $\begin{array}{l}\text { A Constituição da identidade na } \\
\text { pós-modernidade: o simulacro da } \\
\text { realidade }\end{array}$ & $\begin{array}{c}\text { Identidade } \\
\text { Simulacro da realidade }\end{array}$ & $\begin{array}{c}\text { Identidade } \\
\text { Nascidos em tempos líquidos }\end{array}$ \\
\hline
\end{tabular}

Fonte: Autores, 2020

O Quadro 4, portanto, foi elaborado para mostrar a tríplice relação que estabelecemos entre as pesquisas estudadas, os conceitos-chaves de Bauman e seus livros. Contudo, é preciso destacar que, no conjunto de sua obra, o sociólogo polonês retoma vários dos temas em diferentes escritos que se complementam ou se entrecruzam.

Deste modo, os títulos indicados na coluna da direita são sugestões de leitura para quem quiser adentrar as discussões, mas não as pretendem encerrar; ao contrário, desejam incitar a um conhecimento mais amplo sobre o que Bauman discute pois, "quando lemos mais 
de uma obra de um mesmo autor, elas vão se complementando em nossa cabeça, ampliando nossa experiência sobre pontos em comum, fragmentos esparsos em todas elas que se complementam na cabeça do leitor" (Maria, 2009, p. 89).

De toda a feitura, entendemos como possível e pertinente a utilização de filmes com fins pedagógicos, nos cursos de formação de professores, para ilustrar, clarificar ou até mesmo problematizar os principais traços da modernidade líquida. $\mathrm{O}$ acervo disponível é muito mais amplo do que o aqui comentado, o que dá ao professor ampla possibilidade de escolha, considerando qual temática e como deseja abordá-la com seus alunos.

\section{Considerações Finais}

A elaboração do estado do conhecimento e as reflexões feitas a partir dele mostraramse um indicativo e um direcionamento importante para nosso trabalho, pois possibilitou uma visão abrangente da temática "Bauman" e "cinema", que posteriormente foi abordada no curso de formação de professores para a construção da dissertação.

Consideramos, tal qual Cassales (2015) o fez em sua pesquisa, que a utilização de um produto cultural, reflexo da sociedade na qual está inserido, cria sua própria forma de externalizar os sentimentos internos da sociedade. Neste sentido, os filmes expõem mais claramente algumas condições da modernidade líquida. Conclusão semelhante expõe Osório (2013), com a qual concordamos, ao destacar que a maneira como a arte (mais especificamente o cinema) se coloca diante da realidade, tentando compreendê-la à sua maneira, é fonte para olhares interpretativos e desveladores.

Ainda, gostaríamos de fazer uma última ressalva: considerando que "a arte fornece ao indivíduo subsídios para amenizar a incerteza em um momento de mutações sociais intensas" da forma que a objetividade não dá conta (Osório, 2013, p. 11), surpreende-nos que quase a totalidade dos filmes analisados nas pesquisas que encontramos olha para outro cinema que não o nacional. É provável que isso aconteça não somente devido à preferência e à escolha dos pesquisadores, mas porque o cinema brasileiro é posto, comercialmente, à margem: comparando os anos de 2019 e 2018, houve um aumento de 7,6\% de público (de 160 milhões para 172,2 milhões), contudo a bilheteria do cinema brasileiro caiu de 22,9 milhões para 22,6 milhões (Matos, 2020).

As questões atinentes à modernidade líquida são globais, porém apresentam nuances distintas em dimensões nacionais e locais. Não se trata de um bairrismo afetivo; é preciso que consideremos que o cinema brasileiro, além da qualidade reconhecida das suas produções em 
festivais da área, tem proximidade ontológica com a cultura brasileira e, por isso, deve ser revisitado no esforço de ajudar a compreender a tessitura das relações líquido-modernas do nosso cotidiano. "Bacurau" (de Kleber Mendonça Filho e Juliano Dornelles, 2019), "Tatuagem" (de Hilton Lacerda, 2013), "O palhaço" (de Selton Mello, 2011) e "O animal cordial" (de Gabriela Amaral de Almeida) são alguns exemplos de produções recentes com histórias cuja centralidade pode ser abordada a partir, respectivamente, dos escritos baumanianos sobre a comunidade, a identidade, a cultura, o trabalho, ou outros tópicos.

Com relação às práticas pedagógicas na e para a pós-modernidade, Lampert (2005) lembra que ela clama por um currículo que se relacione com as questões de classe, raça, gênero, processo, ideologia, indivíduos, hermenêutica, ecologia, teologia, cognição e demais “ismos”; para esses, em nossa opinião, o cinema é um átrio convidativo.

Dado todo o exposto, encerramos dizendo que este artigo almeja ser, ao leitor, um duplo convite: à sociologia de Bauman e à manipulação de obras cinematográficas como metáfora das principais características da modernidade líquida que, tão bem conectadas nas obras aqui discutidas, podem ajudar a clarificar traços e comportamentos da atualidade, contribuindo no processo de formação dos professores. Ainda, ensejamos que este artigo contribua para novos estudos com temática semelhante àquela aqui apresentada.

\section{Referências}

Adelman, M. (2009). Visões da pós-modernidade: discursos e perspectivas teóricas. Sociologias, 21, 184-217. Recuperado de https://www.scielo.br/pdf/soc/n21/09.pdf. doi: https://doi.org/10.1590/S1517-45222009000100009.

Almeida, F. Q., Gomes, I. M., \& Bracht, V. (2016). Bauman e a educação (2a edição). Belo Horizonte: Autêntica.

Appignanesi, R., \& Garratt, C. (1997). Pós-modernismo para iniciantes. Lisboa: Dom Quixote.

Argenti, P. A. F. (2010). “Eu te amo”, a representação do amor pós-moderno no filme de Arnaldo Jabor (Trabalho de conclusão de curso). Faculdade de Biblioteconomia e Comunicação - UFRGS, Porto Alegre, RS, Brasil. 
Bauman, Z. (2011). 44 cartas do mundo líquido moderno. Rio de Janeiro: Jorge Zahar.

Bauman, Z. (2004). Amor líquido: sobre a fragilidade dos laços humanos. Rio de Janeiro: Jorge Zahar.

Bauman, Z. (2018). Ética pós-moderna. São Paulo: Paulus.

Bauman, Z. (2005). Identidade: entrevista a Benedetto Vecchi. Rio de Janeiro: Jorge Zahar.

Bauman, Z. (2001). Modernidade Líquida. Rio de Janeiro: Jorge Zahar.

Bauman, Z. (1994). Sobre educação e juventude. Rio de Janeiro: Jorge Zahar.

Bauman, Z. (2010). Vivemos tempos líquidos: nada é para durar. Recuperado de https://istoe.com.br/102755_VIVEMOS+TEMPOS+LIQUIDOS+NADA+E+PARA+DURAR $+/$

Bauman, Z., \& Donskis L. (2019). Mal líquido. Rio de Janeiro: Jorge Zahar.

Bauman, Z., \& Leoncini, T. (2018). Nascidos em tempos líquidos: transformações no terceiro milênio. Rio de Janeiro: Jorge Zahar.

Cassales, L. P. (2015). A representação do mal-estar líquido no cinema de Michael Haneke (Dissertação de mestrado). Programa de Pós-graduação em Comunicação Social - PUC, Porto Alegre, RS, Brasil.

Colgnachi, M. L. T. (2009). Representações da modernidade líquida em Vicky Cristina Barcelona (Trabalho de conclusão de curso). Faculdade de Biblioteconomia e Comunicação UFRGS, Porto Alegre, RS, Brasil.

Duarte, R. (2002). Cinema e educação. Belo Horizonte: Autêntica.

Eagleton, T. (1998). As ilusões do pós-modernismo. Rio de Janeiro: Jorge Zahar. 
Kurtz, L. N. (2014). A Sociedade líquida e os efeitos do desenvolvimento da Tecnologia: uma análise do filme Wall-e (Trabalho de conclusão de curso). Faculdade de Comunicação - UPF, Passo Fundo, RS, Brasil.

Lampert, E. (2005). Pós-modernidade e educação. In: Lampert, E., Calloni, H., Baumgarten, M., \& Porto, I. (Orgs.). Pós-modernidade e conhecimento: educação, sociedade, ambiente e comportamento humano (Cap. 1, pp. 11-48). Porto Alegre: Sulina.

Fávero, A. A., Tonieto, C., \& Consálter, E. (Orgs.). (2019). Leituras sobre Zygmunt Bauman e a educação. Curitiba: CRV.

Fonseca, J. J. S. (2002). Metodologia da pesquisa científica. Fortaleza: UEC.

Maria, L. de. (2009). O clube do livro: ser leitor - que diferença faz?. São Paulo: Globo.

Matos, T. (2020). Cinema cresce no Brasil em 2019, mas público de filmes brasileiros foi menor que em 2018. Recuperado de https://g1.globo.com/poparte/cinema/noticia/2020/01/14/cinema-cresce-no-brasil-em-2019-mas-publico-de-filmesbrasileiros-foi-menor-que-em-2018.ghtml

Morin, E. (2003). A cabeça bem-feita: repensar a reformar, reformar o pensamento. Rio de Janeiro: Bertrand Brasil.

Morosini, M. C., \& Fernandes, C. M. B. (2014). Estado do conhecimento: conceitos, finalidades e interlocuções. Educação por escrito, 5(2), 154-164. Recuperado de http://revistaseletronicas.pucrs.br/ojs/index.php/porescrito/article/view/18875/12399.

Nascimento, K. L. do, \& Silva, A. D. N. da. (2019). A sociedade líquida e o conceito de felicidade em "A arte da vida” de Zygmunt Bauman. Cadernos Zygmunt Bauman, 9(18), 115 138. Recuperado de http://www.periodicoseletronicos.ufma.br/index.php/bauman/article/view/10945/7535 
Oliveira, F. M. D. (2016). A Constituição da Identidade na Pós-modernidade: o simulacro da realidade (Dissertação de mestrado). Programa de Pós-graduação em Ciências Sociais UFU, Uberlândia, MG, Brasil.

Osório, M. C. (2013). Maria Antonieta: uma abordagem cinematográfica do indivíduo contemporâneo (Dissertação de mestrado). Programa de Pós-graduação em Comunicação Social - PUC, Porto Alegre, RS, Brasil.

Palhares, E. R. (2010). Blade Runner: a ficção científica e a ética da ciência na sociedade líquido-moderna (Dissertação de mestrado). Programa de Pós-graduação em Ciências Sociais - PUC, São Paulo, SP, Brasil.

Pereira, A. S., Shitsuka, D. M., Parreira, F. J., \& Shitsuka, R. (2018). Metodologia da pesquisa científica. [e-book]. Santa Maria. Ed. UAB/NTE/UFSM. Recuperado de: https://repositorio.ufsm.br/bitstream/handle/1/15824/Lic_Computacao_MetodologiaPesquisa-Cientifica.pdf?sequence $=1$.

Sá, O., \& Retz, R. de G. (2015). Introdução a Bauman: o mundo como texto. Quanta, 1(1), 84-108. Recuperado de https://www.aedb.br/publicacoes/index.php/comunicacao/article/view/12/11

Shinn, T. (2008). Desencantamento da modernidade e da pós-modernidade: diferenciação, fragmentação e a matriz de entrelaçamento. Scientiae studia, 6(1), 43-81. Recuperado de https://www.scielo.br/pdf/ss/v6n1/a02v06n01.pdf. doi: https://doi.org/10.1590/S167831662008000100003

\title{
Porcentagem de contribuição de cada autor no manuscrito
}

\author{
Rafael Montoito - 60\% \\ Luize Castro Garim - $40 \%$
}

